\title{
Short Periods of Hypoxia Upregulate Sphingosine Kinase 1 and Increase Vasodilation of Arteries to Sphingosine 1-Phosphate $(\mathrm{S} 1 \mathrm{P})$ via $\mathrm{S}_{1} \mathrm{P}_{3} \mathrm{\Phi}$
}

\author{
H. Alganga, T.A.M. Almabrouk, O.J. Katwan, C.J. Daly, @S. Pyne, @N.J. Pyne, \\ and (1)S. Kennedy
}

Institute of Cardiovascular and Medical Sciences, College of Medical, Veterinary \& Life Sciences, University of Glasgow, Glasgow, United Kingdom (H.A., T.A.M.A., O.J.K., C.J.D., S.K.); Strathclyde Institute of Pharmacy and Biomedical Science, University of Strathclyde, Glasgow, United Kingdom (S.P., N.J.P.); Department of Pharmacology, School of Medicine, University of Zawia, Zawia, Libya (H.A., T.A.M.A.); and Department of Biochemistry, College of Medicine, University of Diyala, Baqubah, Iraq (O.J.K.)

Received March 6, 2019; accepted July 30, 2019

\begin{abstract}
Sphingosine kinase [(SK), isoforms SK1 and SK2] catalyzes the formation of the bioactive lipid, sphingosine 1-phosphate (S1P). This can be exported from cells and bind to S1P receptors to modulate vascular function. We investigated the effect of shortterm hypoxia on SK1 expression and the response of arteries to S1P. SK1 expression in rat aortic and coronary artery endothelial cells was studied using immunofluorescence and confocal microscopy. Responses of rat aortic rings were studied using wire myography and reversible hypoxia induced by bubbling myography chambers with $95 \% \mathrm{~N}_{2}: 5 \% \mathrm{CO}_{2}$. Inhibitors were added 30 minutes before induction of hypoxia. S1P induced endothelium-dependent vasodilation via activation of $\mathrm{S}_{1} \mathrm{P}_{3}$ receptors and generation of nitric oxide. Hypoxia significantly increased relaxation to S1P and this was attenuated by $(2 R)-1-$ [[(4-[[3-methyl-5-[(phenylsulfonyl)methyl] phenoxy]methyl]phenyl]methyl]-2-pyrrolidinemethanol [(PF-543), SK1 inhibitor] but
\end{abstract}

not $(R)$-FTY720 methyl ether [(ROMe), SK2 inhibitor]. Hypoxia also increased vessel contractility to the thromboxane mimetic, 9,11-dideoxy-11 $\alpha, 9 \alpha$-epoxymethanoprostaglandin F2 $\alpha$, which was further increased by PF-543 and ROMe. Hypoxia upregulated SK1 expression in aortic and coronary artery endothelial cells and this was blocked by PF- 543 and 2-(p-hydroxyanilino)-4-(p-chlorophenyl)thiazole [(SKi), SK1/2 inhibitor]. The effects of PF-543 and SKi were associated with increased proteasomal/lysosomal degradation of SK1. A short period of hypoxia increases the expression of SK1, which may generate S1P to oppose vessel contraction. Under hypoxic conditions, upregulation of SK1 is likely to lead to increased export of S1P from the cell and vasodilation via activation of endothelial $\mathrm{S}_{1} \mathrm{P}_{3}$ receptors. These data have significance for perfusion of tissue during episodes of ischemia.

\section{Introduction}

Sphingosine 1-phosphate (S1P) is a bioactive lipid formed by phosphorylation of sphingosine, catalyzed by two isoforms of sphingosine kinase (SK), SK1 and SK2. Intracellularly, S1P binds to target proteins such as histone deacetylase $1 / 2$, while extracellular S1P activates specific G protein-coupled receptors ( $\mathrm{S} 1 \mathrm{P}$ receptor types $1-5)$, of which $\mathrm{S}_{1} \mathrm{P}_{1}, \mathrm{~S}_{1} \mathrm{P}_{2}$, and $\mathrm{S}_{1} \mathrm{P}_{3}$ are localized within the cardiovascular system (Pyne and

H.A. and T.A.M.A. were supported by a scholarship from the Libyan Government. O.J.K. was sponsored by a scholarship from the Iraqi Government.

https://doi.org/10.1124/jpet.119.257931.

S This article has supplemental material available at jpet.aspetjournals.org.
Pyne, 2011). Endothelial cells express mainly ${\mathrm{S} 1 \mathrm{P}_{1}}_{1}$, less $\mathrm{S}_{1} \mathrm{P}_{3}$, and very few $\mathrm{S} \mathrm{P}_{2}$ receptors under normal conditions. In contrast, ${\mathrm{S} 1 \mathrm{P}_{2}}_{2}$ receptors are predominately expressed on vascular smooth muscle cells (VSMCs) with lesser expression of $\mathrm{S}_{1} \mathrm{P}_{1}$ and $\mathrm{S}_{1} \mathrm{P}_{3}$ (Alewijnse and Peters, 2008). Previous studies have shown that exogenous S1P stimulates both vasodilation and vasoconstriction with the net effect being dependent on the specific vascular bed, species, S1P concentration, and S1P receptors expressed. S1P induces vasoconstriction in rat mesenteric (Hemmings et al., 2004) and cerebral (Salomone et al., 2008) arteries, and in rat coronary arteries via activation of $\mathrm{S} \mathrm{P}_{3}$ receptors on VSMCs (Murakami et al., 2010). In contrast, nitric oxide (NO)-dependent vasorelaxation to $\mathrm{S} 1 \mathrm{P}$ has been reported in rat mesenteric

ABBREVIATIONS: AU, absorbance unit; CA-074ME, N-(L-3-trans-propylcarbonyl-oxirane-2-carbonyl)-L-isoleucyl-L-proline methyl ester; CYM5541, N,N-dicyclohexyl-5-cyclopropyl-3-isoxazolecarboxamide; em, emission; eNOS, endothelial nitric oxide synthase; ex, excitation; FTY720, 2-amino-2-[2-(4-octylphenyl)ethyl]propane-1,3-diol; L-NNA, L-NG-nitroarginine; MG132, carbobenzoxy-Leu-Leu-leucinal; NO, nitric oxide; NOS, nitric oxide synthase; PF-543, (2R)-1-[[(4-[[3-methyl-5-[(phenylsulfonyl)methyl] phenoxy]methyl]phenyl]methyl]-2-pyrrolidinemethanol; ROMe, $(R)$-FTY720 methyl ether; SEW2871, 5-[4-phenyl-5-(trifluoromethyl)thiophen-2-yl]-3-[3-(trifluoromethyl)phenyl]1,2,4-oxadiazole; SK, sphingosine kinase; SKi, 2-(p-hydroxyanilino)-4-(p-chlorophenyl)thiazole; S1P, sphingosine 1-phosphate; U46619, 9,11-dideoxy-11 $\alpha$,9 $\alpha$-epoxymethanoprostaglandin F2 $\alpha$; VSMC, vascular smooth muscle cells. 
vessels (Dantas et al., 2003), which in the rat aorta is mediated via $\mathrm{S}_{1} \mathrm{P}_{3}$ receptors (Nofer et al., 2004).

The expression of SK represents a key node in regulation of the relative levels of sphingosine (its substrate), ceramide (precursor to sphingosine), and S1P, termed the sphingolipid rheostat. SK1 and SK2 differ substantially in their tissue expression, substrate preferences, inhibitor specificities, kinetic properties, and subcellular localization (Kohama et al., 1998; Liu et al., 2000). SK1 is predominately localized in the cytoplasm of cells (Kohama et al., 1998; Olivera et al., 1998). In response to agonist stimulation, SK1 is phosphorylated, activated several fold, and translocated to the plasma membrane (Pitson et al., 2003). In contrast, SK2 contains nuclear localization and nuclear export signals (Igarashi et al., 2003; Ding et al., 2007). Interestingly, some studies have reported that compounds inhibiting SK also induce proteasomal and/or lysosomal degradation of SK1 (Loveridge et al., 2010; Ren et al., 2010; Tonelli et al., 2010).

Generally, S1P functions as a prosurvival signal, while sphingosine and ceramide are associated with proapoptotic pathways and are important regulators of cell stress responses (Hannun and Obeid, 2002). Indeed, there is a wealth of evidence showing the beneficial effects of activating the SK/S1P pathway on cardiomyocyte survival under ischemic conditions (reviewed in Karliner (2013)) as well as chronic effects on cardiac remodeling (reviewed in $\mathrm{Li}$ and Zhang (2016)). Hypoxia, as a result of a transient interruption of the blood supply, upregulates SK activity in human pulmonary artery smooth muscle cells (Ahmad et al., 2006), the brain microvasculature (Wacker et al., 2009), cultured cardiomyocytes (Zhang et al., 2016), and remodeled pulmonary arteries from humans and rats with pulmonary hypertension (Gairhe et al., 2016). The increased generation of S1P, due to upregulation of SK1 in hypoxic cells, is likely to release S1P, which might act on $\mathrm{S} 1 \mathrm{P}$ receptors in a paracrine manner on these cells. To date, the effects of hypoxia on SK expression within arterial endothelium and the consequences for vascular function have not been investigated. Since reoxygenation of ischemic tissues will be via blood supplied by the vasculature, there is a need to study the effects of hypoxia on the SK/ S1P pathway.

Several studies have shown that hypoxia causes dilation of the coronary arteries in isolated whole heart preparations (Daut et al., 1990; Gasser et al., 1998). However, results in isolated coronary arteries exposed to hypoxia were not consistent, with some showing dilation (Kerkhof et al., 2002; Lynch et al., 2006) and others constriction (Gräser and Vanhoutte, 1991; Muramatsu et al., 1992). In denuded rings, hypoxia may induce dilation via inhibition of L-type $\mathrm{Ca}^{2+}$ channels (Herrera and Walker, 1998) or reduced $\mathrm{Ca}^{2+}$ efflux through voltage-gated calcium channels (Franco-Obregón and LópezBarneo, 1996). In endothelium-intact vessels from rat and canine vascular beds, hypoxia stimulates the release of relaxing factors such as prostacyclin (Busse et al., 1983; Messina et al., 1992). S1P generated in response to hypoxia may modulate vascular tone through activation of S1P receptors, the generation of other vasoactive mediators, or perhaps changes in membrane potential of the endothelium by activation of $\mathrm{BK}_{\mathrm{Ca}}$ channels (Kim et al., 2006).

In summary, the mechanisms underlying hypoxia-induced effects on the vasculature remain controversial and require further study. Here, we examined the effect of short, reversible hypoxia on vascular contraction and relaxation in rat aortic rings and the role that $\mathrm{S} 1 \mathrm{P}$ might play in observed changes. Specifically, we studied the effect of hypoxia on SK1 expression in the endothelium and whether SK inhibitors influence how hypoxia alters vascular function.

\section{Materials and Methods}

Tissue Preparation. All animal experiments were performed in accordance with the United Kingdom Home Office Legislation under the Animals (Scientific Procedure) Act 1986 (project license 70/8572) and guidelines from Directive 2010/63/EU of the European Parliament on the protection of animals used for scientific purposes. Male Sprague-Dawley rats were purchased from ENVIGO (UK) and maintained at approved facilities at the University of Glasgow.

To prepare arterial samples for functional or immunofluorescence studies, rats (200-250 g body weight) were killed by a percussive blow to the head followed by cervical dislocation and the heart and thoracic aorta were rapidly removed and placed into cold Krebs' solution $(\mathrm{NaCl}$ $118 \mathrm{mM}, \mathrm{NaHCO}_{3} 25 \mathrm{mM}$, KCl $4.7 \mathrm{mM}, \mathrm{KH}_{2} \mathrm{PO}_{4} 1.2 \mathrm{mM}, \mathrm{MgSO}_{4}$ $1 \mathrm{mM}$, glucose $11 \mathrm{mM}$, and $\mathrm{CaCl}_{2} 2.5 \mathrm{mM}$ ). The thoracic aorta was dissected and cleaned of surrounding fat and connective tissue and cut into 2 to $3 \mathrm{~mm}$ rings. Under a binocular microscope, the right and left coronary arteries were carefully dissected free of connecting heart tissue with fine dissecting scissors and 1 to $2 \mathrm{~mm}$ rings were prepared.

Aortic Functional Studies. Aortic rings were mounted in a fourchannel wire myograph (Danish Myo Technology, Aarhus, Denmark). In some experiments, the endothelium was removed by gentle rubbing of the intimal surface with forceps. Relaxation to acetylcholine $<10 \%$ was indicative of successful endothelial removal. Vessels were incubated at $37^{\circ} \mathrm{C}$ in Krebs' buffer with constant supply of $95 \% \mathrm{O}_{2}$ and $5 \% \mathrm{CO}_{2}$ and equilibrated for 30 minutes before being placed under optimum resting tension of $1 \mathrm{~g}(9.8 \mathrm{mN})$ for a further 30 minutes. Viability was tested by two additions of $40 \mathrm{mM} \mathrm{KCl}$. Contraction and relaxation responses were recorded on Chart 5 Pro software (ADInstruments, UK) and analyzed using Graphpad Prism software.

Experimental Protocols. Aortic rings were returned to baseline tension and exposed to either normal gassing (continuous gassing with $95 \% \mathrm{O}_{2}$ and $5 \% \mathrm{CO}_{2}$ ) or a 30 -minute period of hypoxia. Hypoxia was induced by bubbling the myograph chamber with a mixture of $95 \% \mathrm{~N}_{2}$ and $5 \% \mathrm{CO}_{2}$. In pilot experiments, oxygen saturation was measured continuously in the organ bath using Optical Oxygen Meter-Fire Sting $\mathrm{O}_{2}$ (Pyro Science, Germany) and 30 minutes of hypoxia was found to reproducibly reduce oxygen saturation to below $5 \%$. After 30 minutes, the gas mixture was returned to $95 \% \mathrm{O}_{2}$ and $5 \% \quad \mathrm{CO}_{2}$ and the experiment was commenced. A 30-minute period of hypoxia is commonly used in in vitro studies of artery function (Marriott, 1989; Pyla et al., 2015).

The effect of hypoxia on vessel contractility was assessed using the thromboxane $\mathrm{A}_{2}$ mimetic 9,11-dideoxy-11 $\alpha, 9 \alpha$-epoxymethanoprostaglandin F2 $\alpha$ (U46619) (Coleman et al., 1981). Concentration-response curves were generated by cumulative addition of $\mathrm{U} 46619\left(1 \times 10^{-9}-1\right.$ $\left.\times 10^{-6} \mathrm{M}\right)$ at 10 -minute intervals. To study the effect of hypoxia on the response to $\mathrm{S} 1 \mathrm{P}$ or $\mathrm{S} 1 \mathrm{P}$ receptor agonists, vessels were preconstricted to $5 \times 10^{-8} \mathrm{M} \mathrm{U} 46619$ or in rings previously exposed to hypoxia to $5 \times 10^{-9} \mathrm{M} \mathrm{U} 46619$, since these rings were more sensitive to the constrictor effects of U46619 (data presented in Fig. 1A). This ensured that the effects of vasodilator agents could be compared in rings preconstricted to the same level. Once a stable level of contraction had been reached, cumulative addition of either S1P, the selective $\mathrm{S} 1 \mathrm{P}_{3}$ agonist $N, N$-Dicyclohexyl-5-cyclopropyl-3-isoxazolecarboxamide (CYM5541) (Jo et al., 2012), or the selective $\mathrm{S}_{1} \mathrm{P}_{1}$ receptor agonist 5-[4phenyl-5-(trifluoromethyl)thiophen-2-yl]-3-[3-(trifluoromethyl)phenyl]1,2,4-oxadiazole (SEW2871) (Sanna et al., 2004) was commenced. Agonists were added in a concentration range between $1 \times 10^{-9}$ and $3 \times 10^{-6} \mathrm{M}$ in half-log molar increments with 5 minutes between additions. 


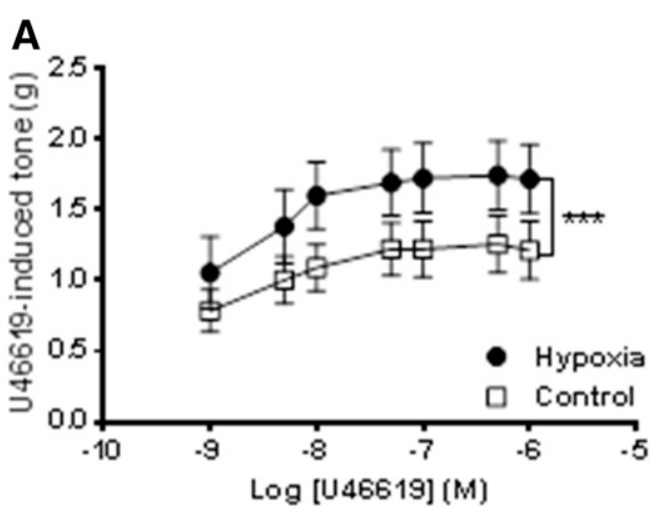

B

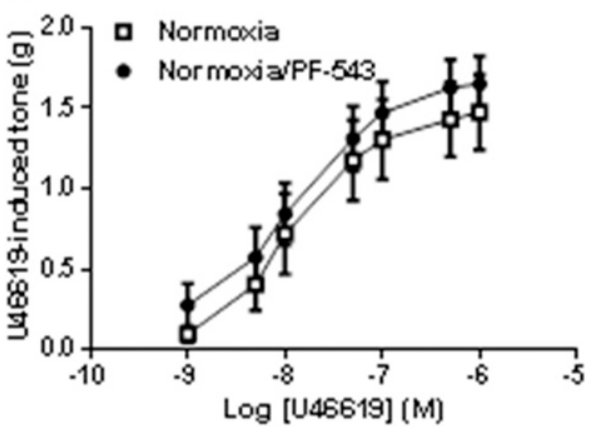

D

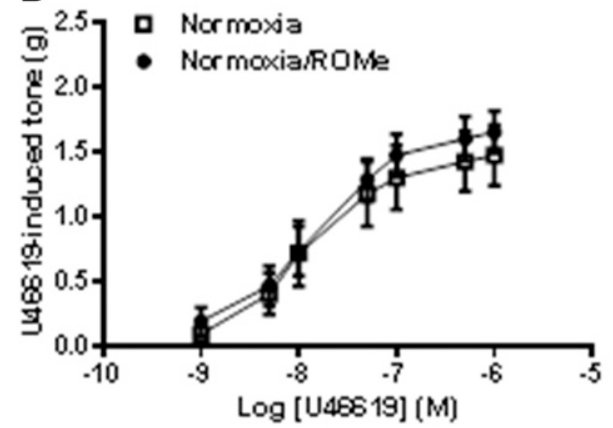

C

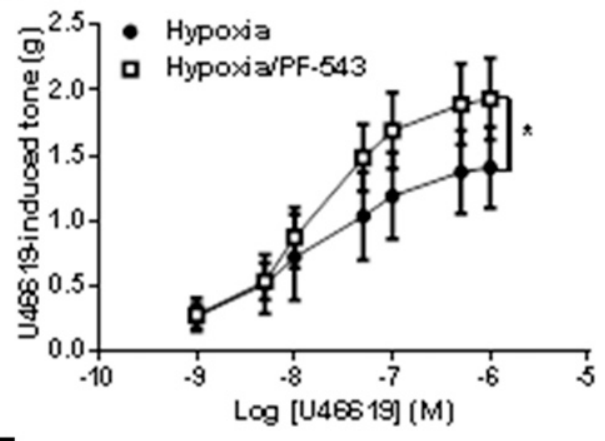

E

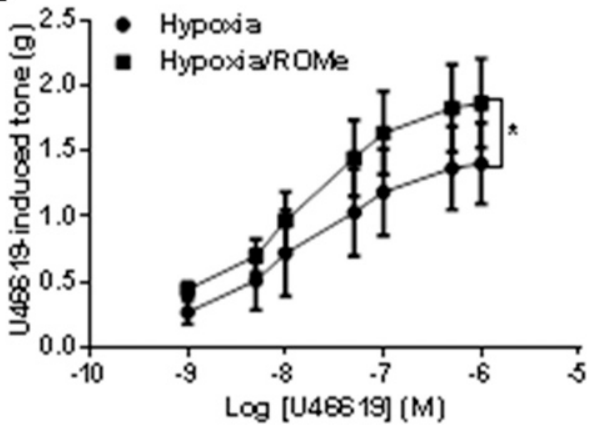

Fig. 1. (A) Exposure of endotheliumintact rat aortic rings to 30 minutes of hypoxia significantly enhanced the contractile response to the thromboxane A2 mimetic U46619 ( $n=8$ for control and $n=9$ for hypoxia). Addition of the selective SK1 inhibitor PF-543 (100 nM) had no effect on contraction under control conditions (B) but significantly increased contraction in vessels previously exposed to hypoxia (C); $n=5$. Similarly, the selective SK2 inhibitor ROMe $(10 \mu \mathrm{M})$ had no effect under control conditions (D), but significantly increased contraction in vessels previously exposed to hypoxia conditions (E); $n=5$. Data are expressed as mean \pm S.E.M. for $n$ arteries from different animals. $* P<0.05 ; * * * P<$ 0.001 vs. control determined by two-way ANOVA.
To assess the effects of SK1 and SK2 inhibitors on contraction under hypoxia and normoxia, $(2 R)-1-[[(4-[[3-m e t h y l-5-[($ phenylsulfonyl)methyl] phenoxy]methyl]phenyl]methyl]-2-pyrrolidinemethanol [(PF-543), $100 \mathrm{nM}$; SK1 inhibitor] Schnüte et al., 2012) or (R)-FTY720 (2-amino-2[2-(4-octylphenyl)ethyl]propane-1,3-diol) methyl ether [(ROMe), $10 \mu \mathrm{M}$; SK2 inhibitor] Lim et al., 2011) was added 15 minutes before exposure to hypoxia (30 minutes with return to normoxia) and was present during generation of the concentration-response curve to U46619 $\left(1 \times 10^{-9}-1 \times 10^{-6} \mathrm{M}\right)$. To determine the effects on relaxation of PF543 and ROMe, the SK1/2 dual inhibitor 2-(p-hydroxyanilino)-4( $p$-chlorophenyl)thiazole (SKi), cycloheximide (French et al., 2003), or the NO synthase (NOS) inhibitor L-NG-nitroarginine (L-NNA) (Furfine et al., 1993), was added 30 minutes prior to contraction with $\mathrm{U} 46619\left(5 \times 10^{-8} \mathrm{M}\right)$, and were present throughout. The effect of the inhibitors on relaxation was also carried out in rings subjected to hypoxia and then submaximally contracted with $\mathrm{U} 46619\left(5 \times 10^{-9} \mathrm{M}\right)$. Once a plateau was achieved, concentration-response curves were performed by cumulative addition of S1P or other agonists.

Immunofluorescence. Confocal microscopy was used to identify expression and distribution of $\mathrm{SK} 1, \mathrm{~S}_{1} \mathrm{P}_{1}$, and $\mathrm{S}_{1} \mathrm{P}_{3}$ receptors in aortic endothelium as well as SK1 expression in coronary artery endothelium; this technique has been used successfully in whole blood vessels in other studies (Arribas et al., 2007). Briefly, aortic or coronary rings were opened longitudinally, fixed overnight, washed, and blocked for 2 hours in $10 \%$ normal goat serum followed by primary antibody against the protein of interest overnight at $4^{\circ} \mathrm{C}$. Primary antibodies were diluted in PBS supplemented with $1 \%$ bovine serum albumin and used at a dilution of 1:50 (SK1, $\mathrm{S}_{1} \mathrm{P}_{1}$, and $\mathrm{S}_{1} \mathrm{P}_{3}$ ) or 1:100 (phosphoSK1). Sections were washed and incubated with AlexaFluor 594 or AlexaFluor 647 (for $\mathrm{S}_{1} \mathrm{P}_{1}$ and $\mathrm{S}_{1} \mathrm{P}_{3}$ receptor staining) conjugated goat anti-rabbit secondary antibody for 1 hour at room temperature (1:250 diluted in PBS $+1 \%$ bovine serum albumin with $1 \mu \mathrm{M}$ of Syto 61 or Syto 82 for S1P receptor staining). Use of Syto nuclear stains allowed differentiation of endothelial and smooth muscle cell nuclei based on shape and position. To avoid crosstalk and bleed-through of fluorescent probes, the nuclear stain Syto 82 (red fluorescent) was paired with AlexaFluor 647 (far-red fluorescent) and Syto 61 (far-red fluorescent) was paired with AlexaFluor (red fluorescent).

To study the effect of hypoxia on SK1, phosphorylated SK1, and $\mathrm{S}_{1} \mathrm{P}_{1}$ and $\mathrm{S}_{1} \mathrm{P}_{3}$ receptor expression, aortic or coronary rings were placed in a tube containing $1 \mathrm{ml}$ of Krebs' solution and constantly bubbled with $95 \% \mathrm{~N}_{2}$ and $5 \% \mathrm{CO}_{2}$ to a measured oxygen tension of $1 \%-1.5 \% \mathrm{O}_{2}$ saturation. Hypoxia was maintained for 30 minutes and the temperature was held at $37^{\circ} \mathrm{C}$. Arteries were then fixed in $3 \%$ paraformaldehyde and immunostained as outlined previously. 
Artery samples were laid flat on a microscope slide with the endothelial side uppermost. A small well was created using grease and filled with Krebs' solution. A coverslip was placed on the top, creating a chamber. Samples were visualized using a Bio-Rad 2100 Confocal Laser Scanning Microscope fitted with a red diode, green $\mathrm{HeNe}$, and blue argon ion lasers and $\times 20$ oil/water immersion lenses. Vessels were imaged from endothelium to the media and at least three images were collected from random areas. Each experiment was repeated at least three times and lambda strobing was used to minimize bleed-through on individual channels. Each fluorescent probe was imaged as close as possible to its excitation (ex) and emission (em) maxima: AlexaFluor 594 secondary antibody (ex $591 \mathrm{~nm}$; em $614 \mathrm{~nm}$ ); AlexaFluor 647 (ex 647 nm; em $667 \mathrm{~nm}$ ); Syto 61 (ex $637 \mathrm{~nm}$; em $660 \mathrm{~nm}$ ), and Syto 82 (ex 541 nm; em $560 \mathrm{~nm}$ ). For analysis, two-dimensional images were produced (8-bit image depth), where each pixel represents an intensity value between 0 (black) and 255 (white) using a grayscale look-up table. Image J software (Schneider et al., 2012) was used to analyze the integrated density (a measure of total fluorescence intensity) in images taken from different areas in each artery and calculate a mean value.

To investigate the mechanisms involved in regulation of SK in an artery more relevant to ischemia/reperfusion, a series of experiments was carried out using rat coronary arteries. The coronary arteries were preincubated with the following compounds (all at $10 \mu \mathrm{M}$ for 30 minutes): the protein synthesis inhibitor cycloheximide, the proteasomal inhibitor carbobenzoxy-Leu-Leu-leucinal (MG132) (Loveridge et al., 2010), and the cathepsin B inhibitor N-(L-3-transpropylcarbonyl-oxirane-2-carbonyl)-L-isoleucyl-L-proline methyl ester (CA-074ME) (Ren et al., 2010) or a combination of MG132 and CA-074ME. This was followed by treatment with $10 \mu \mathrm{M}$ SKi or vehicle for 30 minutes and exposure to normoxia/hypoxia for 30 minutes.

Materials. S1P, CYM5541, and SEW2871 were obtained from Tocris Bioscience (Bristol, UK). SKi, cycloheximide, CA-074ME, and PF-543 were obtained from Merck Biosciences Ltd. (Nottingham, UK). MG132 and Alexa-Fluor 594 were obtained from Stratech Scientific Ltd. (Newmarket, UK). The following chemicals were purchased from Sigma-Aldrich (Poole, UK): U46619, acetylcholine, and the NOS inhibitor L-NNA. ROMe was synthesized according to Lim et al. (2011). Primary antibodies to $\mathrm{SK} 1$ (ab71700) and $\mathrm{S}_{1} \mathrm{P}_{1}$ (ab23695) were obtained from Abcam (Cambridge, UK), the antibody to $\mathrm{S}_{3} \mathrm{P}_{3}$ (sc30024) was obtained from Santa Cruz Biotechnology (Heidelberg, Germany), and the antibody to phosphoSK1 (SP1641) was obtained from ECM Biosciences (Versailles, Kentucky). Syto 61 and 82 were supplied by ThermoFisher Scientific (Invitrogen Molecular Probes).

Statistics. Contractile responses to U46619 were expressed as mean \pm S.E.M. in grams. All relaxation responses were reported as a percentage of loss of the tone induced by U46619. Concentrationresponse curves were compared by two-way ANOVA with Bonferroni's post-test. To compare the effect of enzyme inhibitors and antagonists on U44619-induced contraction, one-way ANOVA with Dunnett's post-test was used. Fluorescence data were compared using an unpaired $t$ test or one-way ANOVA with Bonferroni's post-test. In all cases, statistical significance was accepted when $P<0.05$.

\section{Results}

Effect of Hypoxia on Contractile Responses. U46619 $\left(1 \times 10^{-9}\right.$ to $\left.1 \times 10^{-6} \mathrm{M}\right)$ caused concentration-dependent contraction in both endothelium-intact and -denuded aortic rings. Exposure to 30 minutes of hypoxia significantly enhanced the contractile response in intact vessels (Fig. 1A) as well as denuded vessels [maximal contraction $1.4 \pm 0.2 \mathrm{~g}$ under normoxia vs. $2.0 \pm 0.3 \mathrm{~g}$ following hypoxia; $(n=9) ; P<$ 0.05]. To assess whether SK1 and/or SK2 are involved in the enhanced contraction, vessels were pretreated with either 100 $\mathrm{nM}$ of the SK1 selective inhibitor PF-543 or $10 \mu \mathrm{M}$ of the SK2 selective inhibitor ROMe. Under normoxic conditions, neither PF-543 nor ROMe had any effect on contraction in endothelium-intact vessels (Fig. 1, B and D). However, in rings exposed to hypoxia, both PF-543 and ROMe significantly increased contraction in endothelium-intact rings (Fig. 1, C and $\mathrm{E} ; P<0.05)$. This suggests that in vessels exposed to hypoxia, generation of S1P by SK in the endothelium might oppose vessel contraction; an effect that is reduced by SK inhibitors.

Effect of Hypoxia on the Vasodilator Response to S1P. We previously reported a vasodilator response to S1P in the rat coronary artery (Mair et al., 2010), and here we demonstrate vasodilation of a similar magnitude in the rat aorta (Fig. 2A). In denuded vessels, the vasodilator response was almost eliminated (Fig. 2A; $P<0.001$ ). To investigate which $\mathrm{S} 1 \mathrm{P}$ receptor subtype is involved, dose-response curves for a selective $\mathrm{S}_{1} \mathrm{P}_{1}$ agonist, SEW2871 (Sanna et al., 2004), and a selective $\mathrm{S}_{1} \mathrm{P}_{3}$ agonist, CYM5541 (Jo et al., 2012), were constructed in precontracted, endothelium-intact arteries. SEW2871 did not induce any significant vasorelaxation compared with loss of tone in a time control vessel (Fig. 2B), whereas CYM5541 ( $1 \mathrm{nM}$ to $30 \mu \mathrm{M})$ induced concentrationdependent relaxation of a similar magnitude to S1P itself (maximal relaxation $20.2 \% \pm 4.0 \%, n=6$ ) (Fig. 2C). In denuded aortic rings, relaxation in response to CYM5541 was markedly attenuated (Fig. $2 \mathrm{C} ; P<0.001$ ).

Having established that the vasodilator response to S1P in rat aorta is endothelium dependent and possibly mediated by $\mathrm{S}_{\mathrm{P}} \mathrm{P}_{3}$ receptors, we next assessed the effect of hypoxia on the response to S1P. Exposure of endothelium-intact aortic rings to 30 minutes of hypoxia significantly enhanced the maximum relaxation to $3 \times 10^{-6} \mathrm{M} \mathrm{S1P}$ compared with normoxic rings $[19.3 \% \pm 3.1 \%$, in normoxic rings $(n=9)$ vs. $31.8 \% \pm 6.3 \%$ after exposure to hypoxia $(n=10) ; P<0.05$ ]. In denuded aortic rings, where S1P did not induce any significant relaxation (Fig. 2A), hypoxia had no effect (data not shown). Since previous studies have indicated that S1P-induced relaxation may be NO mediated (Dantas et al., 2003; Nofer et al., 2004), endothelium-intact aortic rings were treated with the NO synthase inhibitor L-NNA. Under both normoxic conditions and in vessels exposed to hypoxia, L-NNA significantly attenuated relaxation to $\mathrm{S} 1 \mathrm{P}$ (Fig. 3), suggesting that $\mathrm{S}_{\mathrm{P}} \mathrm{P}_{3}$ receptor activation may mediate relaxation via generation of NO. Immunofluorescence experiments were carried out to study the effect of hypoxia on expression of $\mathrm{S}_{1} \mathrm{P}_{1}$ and $\mathrm{S}_{1} \mathrm{P}_{3}$ receptors on aortic endothelium. $\mathrm{S} \mathrm{P}_{3}$ was expressed at a much lower level compared with $\mathrm{S}_{1} \mathrm{P}_{1}$ and hypoxia increased mean fluorescence intensity for both receptors measured in at least four separate images per group, indicating that short-term treatment with hypoxia increases the expression of $\mathrm{S}_{1} \mathrm{P}_{1}$ and $\mathrm{S}_{1} \mathrm{P}_{3}$ (for $\mathrm{S}_{1} \mathrm{P}_{3}$ the integrated density was $1.1 \times 10^{6}$ absorbance units (AU) in normoxia vs. $3.2 \times 10^{6} \mathrm{AU}$ in hypoxia, while for $\mathrm{S}_{1} \mathrm{P}_{1}$ the integrated density was $2.9 \times 10^{6} \mathrm{AU}$ in normoxia vs. $5.0 \times 10^{6} \mathrm{AU}$ in hypoxia) (Supplemental Fig. 1).

Role of SK in Mediating Relaxation to S1P under Normoxia and Hypoxia. In endothelium-intact rat aortic rings under normoxic conditions, the SK1/2 inhibitor (Gao et al., 2012) SKi $(10 \mu \mathrm{M})$ significantly reduced S1P-induced relaxation the maximal relaxation with SKi was $9.6 \% \pm$ $1.3 \%(n=6)$ vs. $20.8 \% \pm 3.2 \%$ without SKi $(n=10) ; P<$ 0.001]. The hypoxia-enhanced relaxation of endotheliumintact aortic rings to $\mathrm{S} 1 \mathrm{P}$ was also markedly reduced by $\mathrm{SKi}$ 

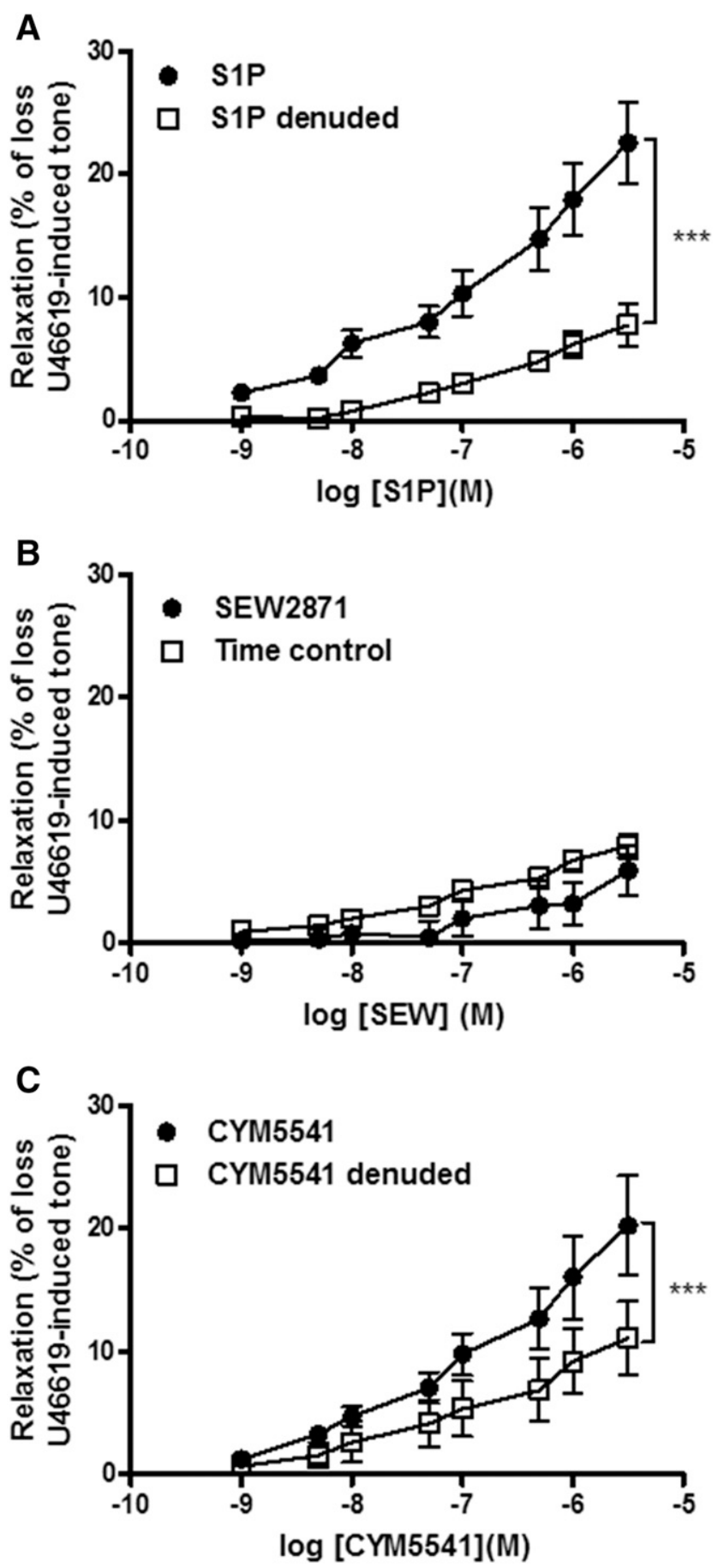

Fig. 2. (A) Addition of S1P to endothelium-intact, U46619-precontracted rat aortic rings induced vasodilation $(n=6)$, which was largely abolished in denuded rings $(n=6)$. (B) The $\mathrm{S}_{1} \mathrm{P}_{1}$ selective agonist SEW2871 did not induce any vasodilation in endothelium-intact aortic rings compared with loss of tone observed in a time control ring ( $n=5$ to 6 ). (C) CYM5541, a selective $\mathrm{S} \mathrm{P}_{3}$ receptor agonist, induced vasodilation of similar magnitude to S1P in endothelium-intact aortic rings. Denudation significantly attenuated the vasodilation in response to CYM5541 $(n=6$ for intact and $n=7$ for denuded). ${ }^{* * *} P<0.001$ vs. S1P alone or CYM5541 alone as determined by two-way ANOVA.

[the maximal relaxation with SKi was $9.5 \% \pm 3.4 \%(n=7)$ vs. $31.8 \% \pm 6.3 \%$ without SKi $(n=10) ; P<0.001]$. To test whether the SK1 or SK2 isoform was important in hypoxiaenhanced vasodilation to $\mathrm{S} 1 \mathrm{P}$, the selective nanomolar-potent
SK1 inhibitor PF-543 (Schnüte et al., 2012) (100 nM) was also studied. As with SKi, PF-543 inhibited relaxation to S1P in endothelium-intact vessels under normoxic conditions [the maximal relaxation with PF-543 was $8.9 \% \pm 2.1 \%(n=9)$ vs. $13.6 \% \pm 1.8 \%$ without PF-543 $(n=8) ; P<0.05]$ and abolished the augmented relaxation to $\mathrm{S} 1 \mathrm{P}$ following exposure to hypoxia (Fig. 4A). In contrast, vasodilator responses to $\mathrm{S} 1 \mathrm{P}$ were unaffected by the selective SK2 inhibitor ROMe $(10 \mu \mathrm{M})$ under both normoxic (data not shown) and hypoxic conditions (Fig. 4B).

Expression of SK in Aortic Endothelium and Effect of Hypoxia. Since hypoxia-enhanced relaxation of endotheliumintact vessels to S1P was blocked by SK1 inhibitors, we sought to establish the effect of hypoxia on SK1 expression in the endothelium using immunofluorescence.

Immunofluorescent staining for SK1 appeared as red punctate staining in the cytosol of the endothelial cells (Fig. 5A). Exposure to hypoxia for 30 minutes resulted in a significant increase (161\%) in SK1 immunostaining compared with arteries maintained under normoxic conditions [integrated density of $2.6 \times 10^{6} \pm 2.6 \times 10^{5} \mathrm{AU}(n=4)$ in hypoxia vs. $1.0 \times$ $10^{6} \pm 1.7 \times 10^{5} \mathrm{AU}(n=4)$ in normoxia; $P<0.01$ ] (Fig. 5B), suggesting that hypoxia increases SK1 levels. In contrast, hypoxia had no effect on phosphorylated-SK1 levels (integrated density of $1.1 \times 10^{6} \pm 1.7 \times 10^{5} \mathrm{AU}, n=3$ ) compared with normoxic vessels (integrated density of $1.0 \times 10^{6} \pm 1.2 \times$ $\left.10^{5} \mathrm{AU}, n=4\right)$. To test whether the hypoxia-induced increase
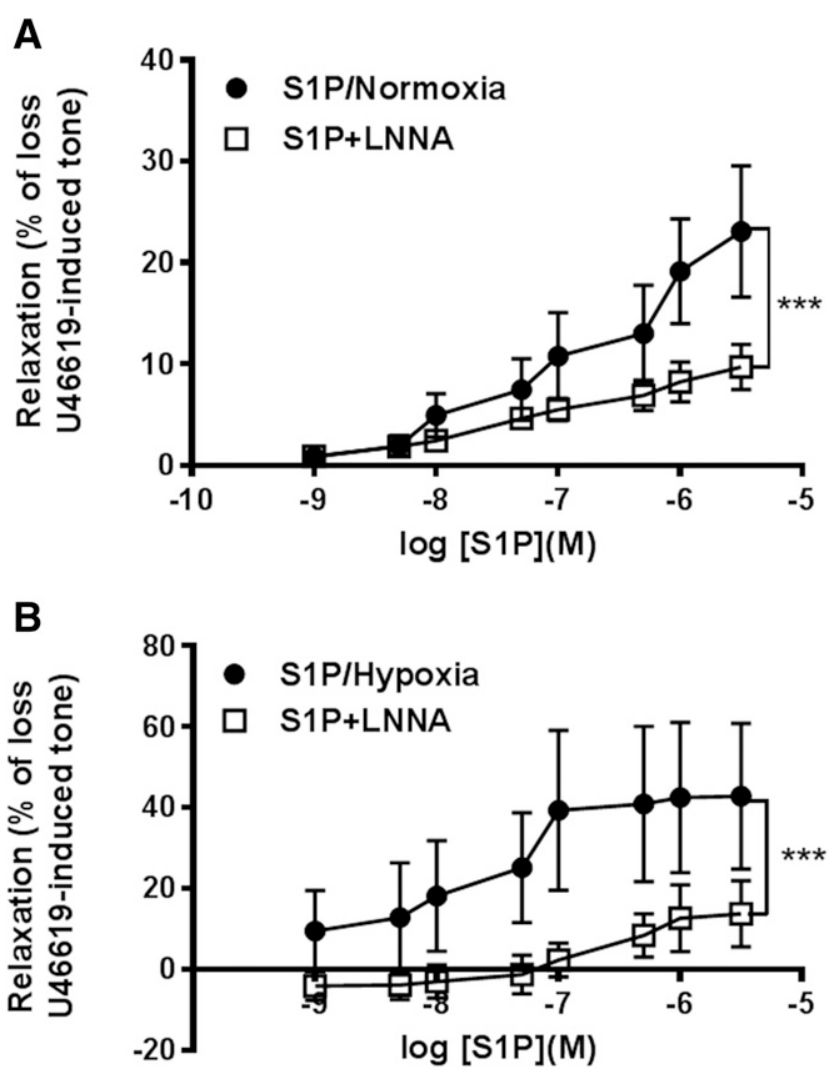

Fig. 3. (A) The NO synthase inhibitor L-NNA $\left(10^{-4} \mathrm{M}\right)$ significantly attenuated the relaxation to S1P in rat aortic rings precontracted with U46619 under normoxic conditions $(n=7)$. (B) After exposure to 30 minutes of hypoxia, the relaxation to $\mathrm{S} 1 \mathrm{P}$ was significantly increased and L-NNA was still able to attenuate the relaxation to $\operatorname{S1P}(n=5$ to 6$)$; *** $P<0.001$ vs. S1P alone as determined by two-way ANOVA. 

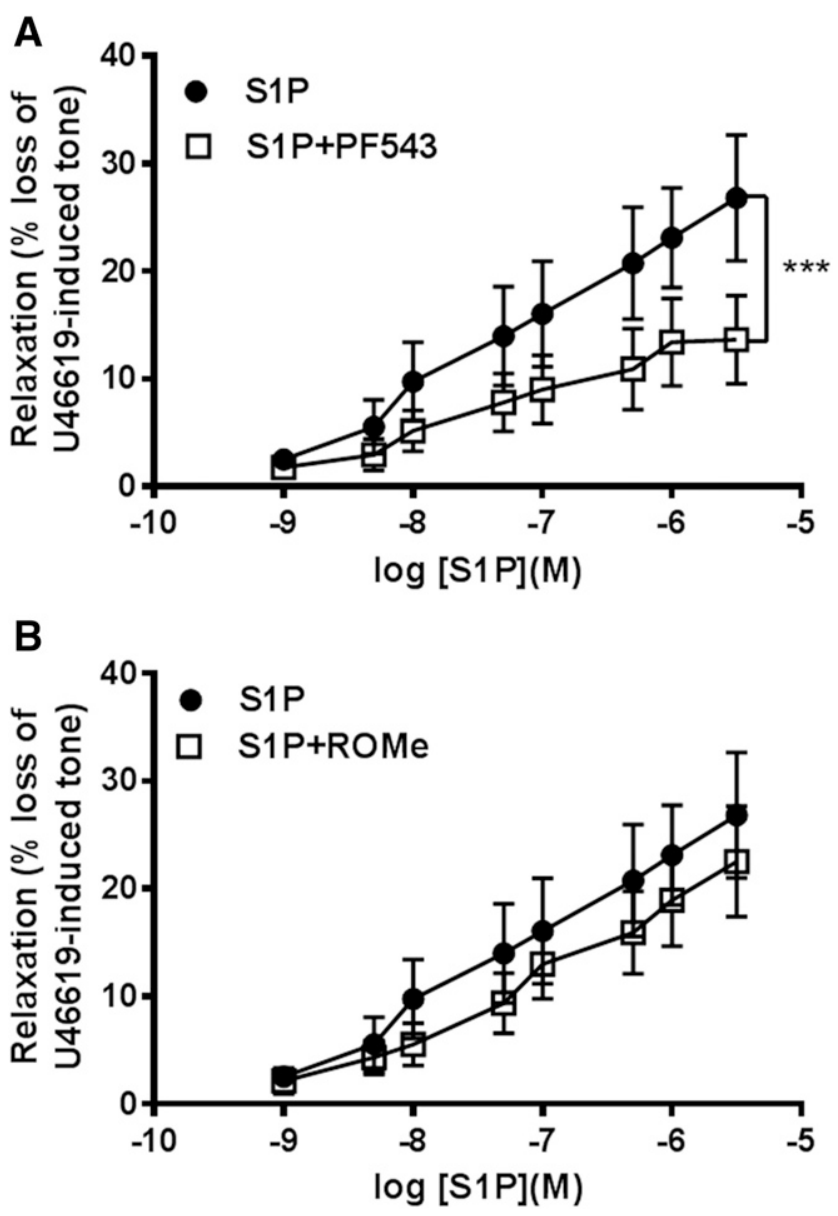

Fig. 4. (A) The selective SK1 inhibitor PF-543 (100 nM) significantly attenuated the relaxation to $\mathrm{S} 1 \mathrm{P}$ in precontracted rat aortic rings exposed to 30 minutes of hypoxia. (B) In contrast, the selective SK2 inhibitor ROMe $(10 \mu \mathrm{M})$ had no effect on S1P-induced relaxation under these conditions ( $n=6$ to 7 for all experiments). *** $P<0.001 \mathrm{vs.} \mathrm{S1P}$ alone as determined by two-way ANOVA.

in SK1 expression required protein synthesis, rings were treated with cycloheximide for 30 minutes prior to exposure to hypoxia for 30 minutes. Under normoxic conditions, cycloheximide had no significant effect on SK1 integrated density (with cycloheximide, $0.83 \times 10^{6} \pm 1.0 \times 10^{5}$ AU vs. $1.0 \times 10^{6} \pm$ $1.7 \times 10^{5}$ AU without cycloheximide, $\left.n=4\right)$. However, cycloheximide significantly attenuated the hypoxia-induced increase in SK1 immunofluorescence (with cycloheximide, $1.3 \times 10^{6} \pm 2.5 \times 10^{5}$ AU vs. $2.6 \times 10^{6} \pm 2.6 \times 10^{5}$ AU without cycloheximide; $n=3$ to $4 ; P<0.01$ ) (Fig. 6 ).

Since SK1 inhibitors attenuated S1P-mediated relaxation under hypoxic conditions, we tested whether this is due to changes in SK1 expression in the endothelium. Under normoxic conditions, pretreatment with the SK1/2 inhibitor SKi $(10 \mu \mathrm{M})$ or PF-543 (100 nM) led to a reduction in SK1 immunostaining. However, analysis of the integrated density did not yield any significant difference (data for PF-543 shown in Fig. 7, A, B, and F). In contrast, SKi or PF-543 (Fig. 7D) significantly reduced the hypoxia-induced increase in SK1 expression (Fig. 7, C and F) when added 30 minutes prior to exposure to hypoxia (the integrated density with SKi was $1.2 \times 10^{6} \pm 1.0 \times 10^{5}$ AU vs. $2.6 \times 10^{6} \pm 2.6 \times 10^{5} \mathrm{AU}$ in the absence of SKi; $n=4 ; P<0.05$ ).

Some SK inhibitors have been reported to not only inhibit the catalytic activity of SK1 but also to induce proteasomal or lysosomal degradation of SK1 (Loveridge et al., 2010; Ren et al., 2010; Tonelli et al., 2010). Hence, we speculated that under hypoxic conditions, PF-543 may increase SK1 degradation and thereby reverse the upregulation of SK1 caused by hypoxia. To test this, a combination of $10 \mu \mathrm{M}$ of the proteasomal inhibitor MG132 and $10 \mu \mathrm{M}$ of the lysosomal inhibitor CA-074ME was added 30 minutes before exposure to hypoxia. Indeed, this combination significantly reversed the attenuating effect of PF-543 on SK1 expression under hypoxic conditions (Fig. 7F).

Expression of SK in Coronary Artery Endothelium and Effect of Hypoxia. As with aortic endothelium, exposure to hypoxia for 30 minutes significantly increased SK1 immunostaining (integrated density of $1.7 \times 10^{6} \pm 2.4 \times 10^{5}$ AU, $n=5 ; P<0.05$ ) compared with arteries under normoxic conditions $\left(1.0 \times 10^{6} \pm 5.2 \times 10^{5} \mathrm{AU}, n=4\right)$. However, in the coronary endothelium, there was also a significant hypoxiainduced increase in phosphorylated-SK1 (integrated density hypoxia of $2.8 \times 10^{6} \pm 2.7 \times 10^{5}$ AU vs. $1.5 \times 10^{6} \pm 1.9 \times 10^{5}$ AU normoxic; $n=3 ; P<0.05$ ).

In coronary arteries, pretreatment with the protein synthesis inhibitor cycloheximide for 30 minutes under normoxic conditions had no significant effect on the SK1 integrated density [with cycloheximide, $0.79 \times 10^{6} \pm 2.1 \times 10^{5} \mathrm{AU}(n=3)$ vs. $1.0 \times 10^{6} \pm 5.2 \times 10^{5}$ AU without cycloheximide $\left.(n=4)\right]$, while under hypoxic conditions there was a significant reduction in the integrated density of SK1 (hypoxia with cycloheximide, $0.68 \times 10^{6} \pm 2.8 \times 10^{5} \mathrm{AU}, n=3 ; P<0.05$ ) compared with hypoxia alone $\left(1.7 \times 10^{6} \pm 2.4 \times 10^{5} \mathrm{AU}, n=5\right)$ (Supplemental Fig. 2).

Under normoxic conditions, pretreatment of coronary arteries with SKi or PF-543 decreased the integrated density of SK1 immunofluorescence, but this was only significant in the case of SKi (Table 1). The selective SK2 inhibitor ROMe had no effect on SK1 expression under normoxic conditions (data not shown). However, both SKi (by 76\%; $P<0.01$ vs. hypoxia alone) and PF-543 (by 73\%; $P<0.01$ vs. hypoxia alone) significantly reduced the increase in SK1 expression caused by hypoxia when added 30 minutes prior to exposure to hypoxia while ROMe had no effect (Fig. 8A).

Pretreatment of coronary arteries with proteasomal or lysosomal inhibitors had no effect on SK1 expression under normoxic conditions and only MG132 reduced the effect of hypoxia on SK1 expression (Table 1). Pretreatment of rat coronary arteries with MG132, CA-074ME, or a combination of MG132 and CA-074ME significantly reversed the effect of SKi on SK1 expression under normoxic conditions (Table 1). Under hypoxia, the SKi-induced reduction in SK1 integrated density was also reversed by MG132, CA-074ME, or a combination of both MG132 and CA-074ME (Fig. 8B).

\section{Discussion}

This study shows that S1P exerts endothelium-dependent vasodilation of rat aorta, which is partly dependent on SK1 activity mediated via $\mathrm{S}_{1} \mathrm{P}_{3}$ receptors and NO release. Exposure to brief reversible hypoxia increases relaxation to $\mathrm{S} 1 \mathrm{P}$, likely via upregulation of SK1 expression in the endothelium and increased generation of S1P. Inhibitors of SK1 (PF-543 and SKi, which inhibit both SK1 and SK2), but not SK2 alone ( $\mathrm{ROMe}$ ), abolished the enhanced relaxation to S1P caused by hypoxia. PF-543 and SKi also reversed the hypoxia-induced 
A

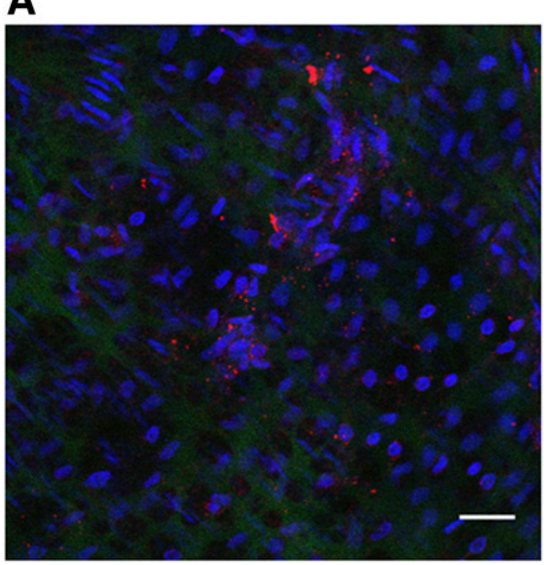

B

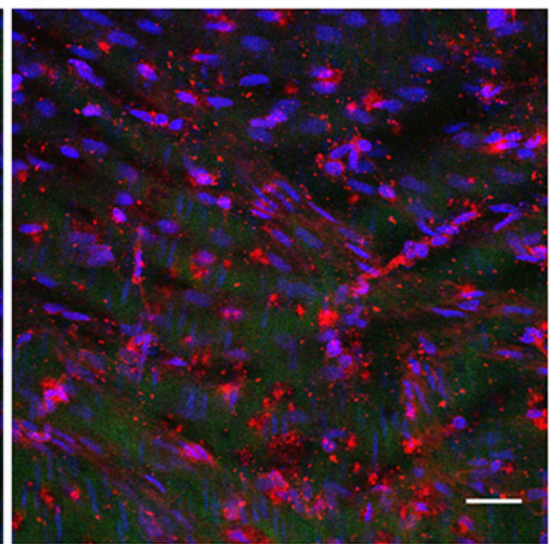

C

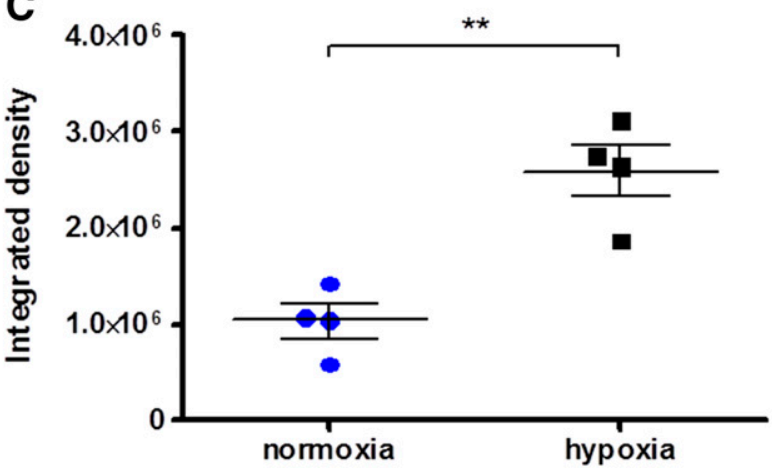

Fig. 5. Representative immunofluorescent images showing expression of SK1 (red) in rat aortic endothelium under normoxic (A) and hypoxic (B) conditions. Nuclei appear blue due to addition of Syto 61 nuclear stain. (C) Quantitative fluorescence measurement of SK1 under normoxia and hypoxia demonstrating the significant increase in SK1 expression caused by exposure to 30 minutes of hypoxia. Scale bar, $30 \mu \mathrm{m}$. $* * P<0.01$ vs. normoxia as determined by unpaired twotailed $t$ test. Results are representative of four separate experiments. upregulation of SK1 by promoting increased proteasomal/ lysosomal degradation of the enzyme. Inhibiting SK also increased contraction in aortic rings exposed to hypoxia, presumably by preventing the generation of the vasodilator S1P in the endothelium. This study demonstrates that the SK/ $\mathrm{S} 1 \mathrm{P}$ system modulates vascular activity in the rat aorta when the vessel is exposed to hypoxia.

A number of studies have reported that hypoxia augments contractile sensitivity to U46619 in isolated cerebral artery (Sillau et al., 2002) and to phenylephrine in isolated rat abdominal aorta (Gräser and Rubanyi, 1993). Here, we found that exposure of endothelium-intact or denuded rat aortic rings to a short period of reversible hypoxia increased contractile sensitivity to U46619. Therefore, in addition to the effects on the endothelium, hypoxia also enhances the sensitivity of VSMCs to U46619. Under normoxic conditions, preincubation of rings with either PF-543 (selective SK1 inhibitor) or ROMe (selective SK2 inhibitor) had no effect on contraction, suggesting that $\mathrm{S} 1 \mathrm{P}$ generation in the endothelium occurs at a low level or is insufficient to oppose contraction to U46619. In endothelium-intact vessels, previously exposed to hypoxia, both SK inhibitors enhanced contraction to U46619, indicating that hypoxia increases activity of the SK/S1P system to oppose vessel contractility.

To test this, we studied responses to S1P in normoxic vessels and those exposed to reversible hypoxia. We confirmed that $\mathrm{S} 1 \mathrm{P}$ induces endothelium-dependent vasorelaxation in rat aorta mediated via $\mathrm{S}_{3} \mathrm{P}_{3}$ receptors. Others have found relaxation to be mediated via $\mathrm{S}_{1} \mathrm{P}_{1}$ receptors (Igarashi and Michel, 2000; Igarashi et al., 2001), while we (Mair et al., 2010) and others (Nofer et al., 2003) have demonstrated a role for
$\mathrm{S}_{1} \mathrm{P}_{3}$ receptors. We found that an $\mathrm{S}_{1} \mathrm{P}_{1}$ agonist failed to induce relaxation while an $\mathrm{S}_{3} \mathrm{P}_{3}$ agonist produced an endotheliumdependent relaxation of a similar magnitude to S1P. Immunofluorescence using anti-S1P $\mathrm{P}_{1}$ and anti-S1P $\mathrm{P}_{3}$ receptor antibodies revealed their expression in aortic endothelial cells with $\mathrm{S}_{3} \mathrm{P}_{3}$ expressed at a lower level in comparison with $\mathrm{S}_{1} \mathrm{P}_{1}$. Interestingly, hypoxia upregulated expression of both receptors, which has been observed in other studies; for example, hypobaric hypoxia upregulated $\mathrm{S}_{3}$ expression after 12 hours but caused a downregulation of $\mathrm{S}_{1} \mathrm{P}_{1}$ in rat lungs (Chawla and Saxena, 2015), while in human umbilical vein endothelial cells exposed to intermittent hypoxia addition of S1P upregulated $\mathrm{S}_{1} \mathrm{P}_{1}$ expression. Although further work is required to confirm our findings, the effect of hypoxia on the expression of $\mathrm{S} \mathrm{P}_{3}$ might contribute to the enhanced relaxation to $\mathrm{S} 1 \mathrm{P}$ in vessels exposed to short periods of hypoxia. Downstream events following $\mathrm{S}_{3} \mathrm{P}_{3}$ receptor activation appear to involve $\mathrm{NO}$ release since L-NNA (NOS inhibitor) attenuated relaxation in control and hypoxia-exposed rings. Several other studies report that endothelial NOS (eNOS) may function as a downstream target for S1P-induced vasorelaxation (di Villa Bianca et al., 2006; Roviezzo et al., 2006) and S1P increases eNOS activity and NO generation in cultured vascular endothelial cells (Igarashi et al., 2001). Our data are consistent with the study by Tölle et al. (2005), where relaxation to the sphingosine analog, FTY720 (which is phosphorylated by SK2), was absent in nnos $^{-1-}$ mice. In addition, relaxation to FTY720 was absent in $S 1 p 3^{-1-}$ mice, providing further evidence that aortic relaxation to $\mathrm{S} 1 \mathrm{P}$ and FTY720 phosphate is via $\mathrm{S}_{1} \mathrm{P}_{3}$. However, since we have not studied the effects of hypoxia on eNOS expression or function, we cannot rule out changes 


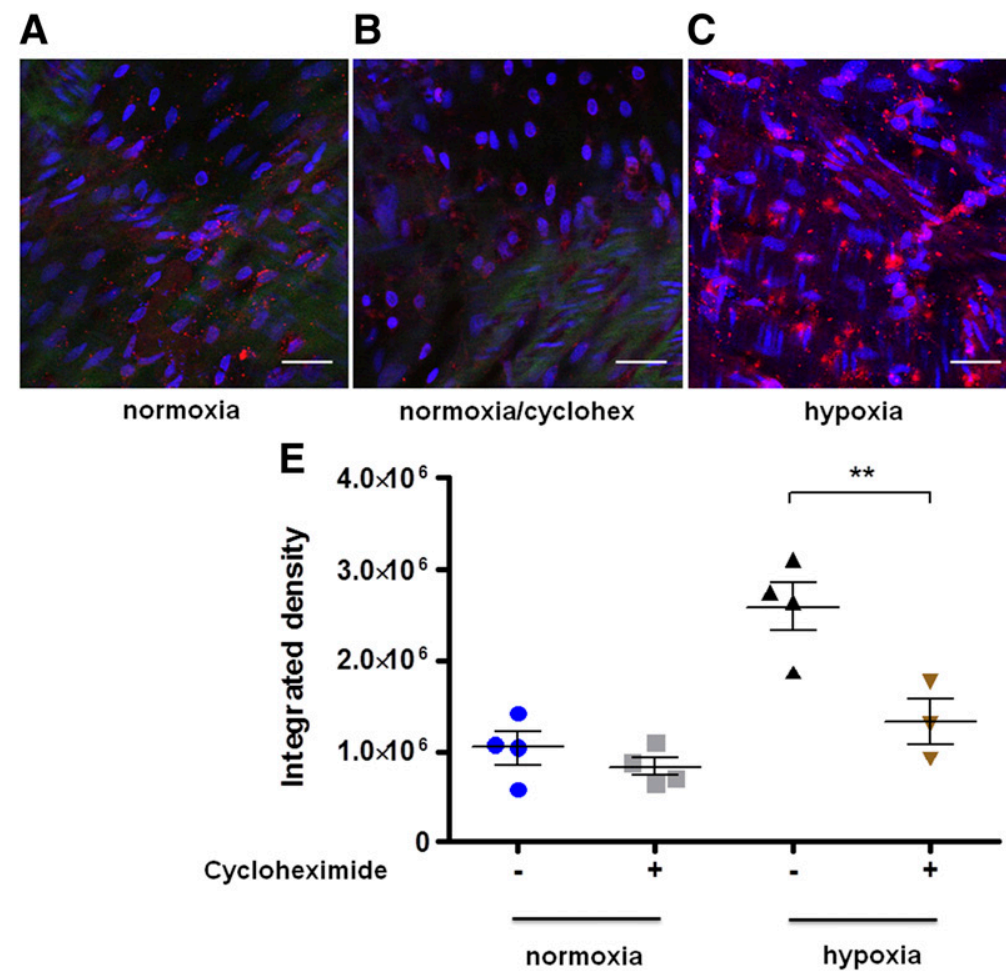

Fig. 6. Representative immunofluorescent images showing expression of SK1 (red) in rat aortic endothelium (A) and following pretreatment with cycloheximide (10 $\mu \mathrm{M}$ for 30 minutes) under normoxic conditions (B). Expression of SK1 in rat aorta subjected to 30 minutes of hypoxia (C). Preincubation with cycloheximide reduced the hypoxia-induced increase in SK1 expression (D). Nuclei appear blue due to addition of Syto 61 nuclear stain. (E) Quantitative fluorescence measurement of SK1 in the presence and absence of cycloheximide. **P<0.01 vs. hypoxia alone as determined by one-way ANOVA with Bonferroni's post-test. Results are representative of three to four separate experiments. Scale bar, $30 \mu \mathrm{m}$.

in the NO dependence of S1P-mediated relaxation caused by hypoxia.

In vessels exposed to reversible hypoxia, vasodilation to S1P was significantly increased. While other studies have reported vasodilator responses in arteries exposed to hypoxia, we are unaware of any reporting vasodilator responses to S1P following brief hypoxia. Induction of hypoxia itself can relax preconstricted vessels, including rat and human coronary arteries (Kerkhof et al., 2002; Lynch et al., 2006), rabbit basilar and carotid arteries (Pearce et al., 1992), and guinea pig and rat aortae (Gasser et al., 1993; Herrera and Walker, 1998). The mechanism of hypoxia-induced vasodilation is unclear; however, in vivo, it probably involves sensing the lowered oxygen saturation linked to a signaling cascade that decreases intracellular $\left[\mathrm{Ca}^{2+}\right]$ and relaxes VSMCs (Totzeck et al., 2014). Here, we applied hypoxia to aortic rings at a resting tension in the absence of constrictor agents. In some rings, a small reversible loss of tone was observed, whereas in others there was no change. In all cases, a return to normoxic conditions reversed any loss of tone prior to adding U46619; this effect was also observed by others (Lynch et al., 2006). The enhanced relaxation to $\mathrm{S} 1 \mathrm{P}$ after hypoxia was not observed in denuded rings, indicating an effect of hypoxia on the endothelium. Previously, we showed that relaxation to S1P in rat coronary artery is blocked by SKi (Mair et al., 2010), and we observed a similar effect in normoxic rat aorta. In vessels exposed to hypoxia, SKi attenuated relaxation, suggesting that SK1 is likely activated by addition of S1P and translocated to the plasma membrane to generate more S1P, which then contributes to endothelium-dependent vasorelaxation through activation of $\mathrm{S} \mathrm{P}_{3}$ and eNOS-generated NO. Further work should establish how hypoxia affects eNOS expression and function in vessel exposed to hypoxia. Our findings suggest privileged access to $\mathrm{S}_{3} \mathrm{P}_{3}$ by $\mathrm{S} 1 \mathrm{P}$ formed by endothelial SK1. To identify whether SK1 or SK2 was important, selective inhibitors were used in hypoxic vessels. Since PF-543 attenuated relaxation to $\mathrm{S} 1 \mathrm{P}$, whereas $\mathrm{ROMe}$ had no effect, we conclude that exposure to hypoxia modulates SK1 in rat aorta. It is interesting that the augmented relaxation to S1P following hypoxia was not sensitive to the SK2 inhibitor ROMe, whereas the increased contraction to U46619 was sensitive to this inhibitor. The difference may be because hypoxia increases mRNA expression of both SK1 and SK2 (Ahmad et al., 2006); therefore, under hypoxic conditions, addition of either PF-543 or ROMe affected the enhanced sensitivity to the thromboxane mimetic U46619. In contrast, S1P has been shown to promote translocation and activation of SK1 (Long et al., 2010) and there is no evidence for a similar regulation of SK2; therefore, this is consistent with the enhanced S1Pmediated relaxation under hypoxic conditions being sensitive to the SK1/SK2 inhibitor, Ski, and the SK1 inhibitor, PF-543, but not the SK2 inhibitor, ROMe. In view of the effects of PF543 on contraction and relaxation in aortic rings exposed to hypoxia, we speculated that hypoxia may upregulate SK1. Indeed, hypoxia was first shown to upregulate SK1 expression in human pulmonary artery smooth muscle cells (Ahmad et al., 2006). A similar upregulation of SK1 in response to hypoxia occurs in glioma cell lines (Anelli et al., 2008), rat amoeboid microglial cells (Lin et al., 2011), and human endothelial cell lines, where SK2 expression is not affected (Schwalm et al., 2008). Here, we observed a pronounced increase in SK1 expression in rat aortic and coronary endothelial cells upon 


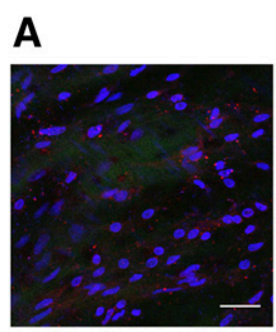

normoxia

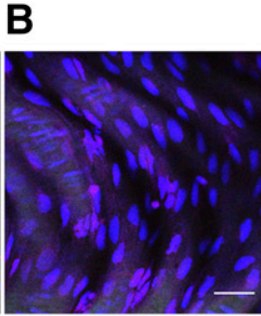

normoxia/PF543

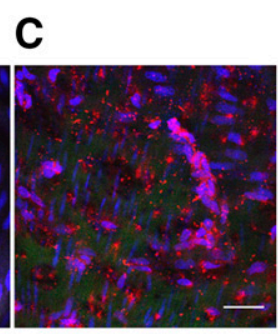

hypoxia
D

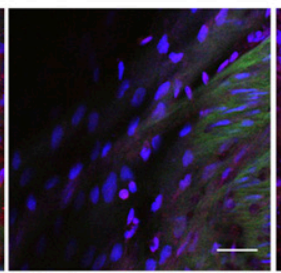

hypoxia/PF543
E

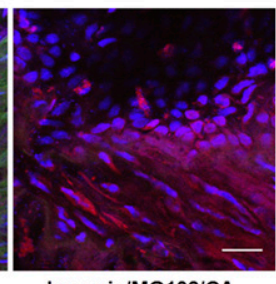

hypoxia/MG132/CA074ME/PF543

\section{$\mathbf{F}$}
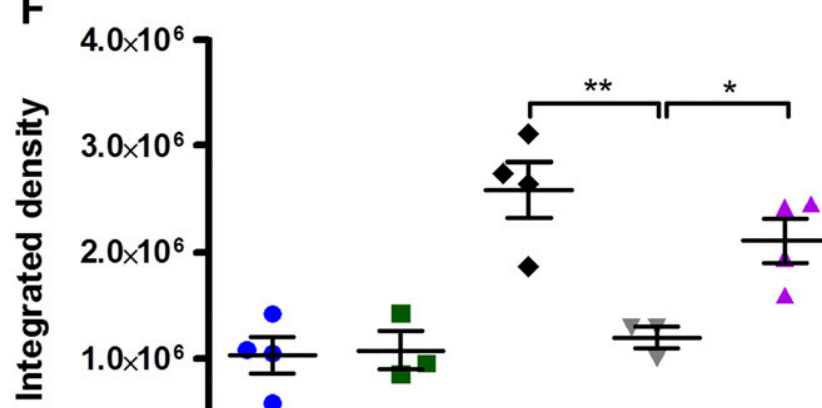

PF543

MG132/CA-074ME

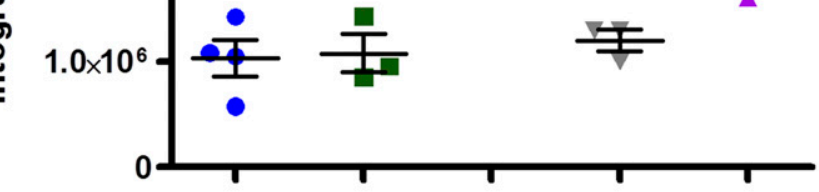

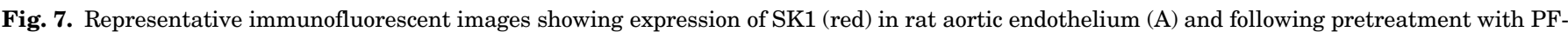

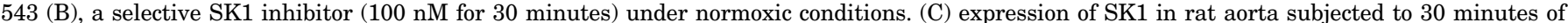

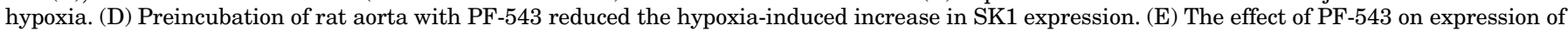

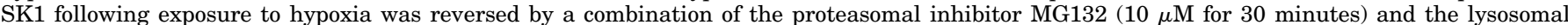

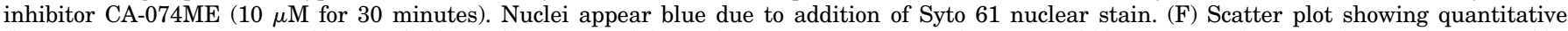

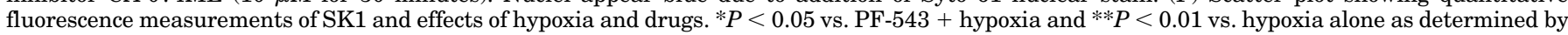
one-way ANOVA with Bonferroni's post-test. Results are representative of three to four separate experiments. Scale bar, $30 \mu \mathrm{m}$ for all images.

30 minutes of hypoxia. This appears to involve rapid protein synthesis since pretreatment with cycloheximide caused a significant reduction in the hypoxia-induced upregulation of SK1. Moreover, the time frame of SK1 upregulation is consistent with other studies where upregulation of SK1 protein and activity commenced within 30 minutes of hypoxia, with peak activity after 1 hour (Anelli et al., 2008).

Cycloheximide had no significant effect on SK1 expression in rings under normoxic conditions, suggesting that turnover of SK1 in endothelial cells is relatively low. In our experiments, we did not see any SK1 immunofluorescence in VSMCs. This is likely due to a lack of antibody penetration since antibody to $\alpha$ SMA also failed to immunostain VSMCs.
Further experiments are required to determine the effect of hypoxia on SK1 expression in medial VSMCs.

We considered that SK1 inhibitors would reduce the upregulation of SK1 expression caused by hypoxia, and indeed we demonstrated this by using both SKi and PF-543. A number of studies have demonstrated that SKi does not only inhibit the catalytic activity of SK1 but also induces SK1 proteasomal or lysosomal degradation, depending on the cell type. For example, Ren et al. (2010) reported that SKi induced lysosomal degradation of SK1 in human endothelial cells, podocytes, and mesangial cells. This was prevented by pretreatment with chloroquine, a general lysosomal inhibitor, and CA-074ME, a specific inhibitor of the lysosomal protease

\section{TABLE 1}

Effect of proteasomal and lysosomal inhibitors on SK1 expression in the rat coronary artery endothelium under normoxic and hypoxic conditions SKi pretreatment (right columns) was $10 \mu \mathrm{M}$ for $30 \mathrm{~min}$. Values of integrated density (absorbance units) are given, mean \pm S.E.

\begin{tabular}{|c|c|c|c|c|}
\hline \multirow{2}{*}{ Treatment } & \multicolumn{4}{|c|}{ Integrated Density (Mean \pm S.E.) } \\
\hline & Normoxia ( $n=3$ to 4 ) & Hypoxia $(n=3-6)$ & Normoxia/SKi ( $n=3-6$ ) & Hypoxia/SKi $(n=3-6)$ \\
\hline No Treatment & $1.0 \times 10^{6} \pm 0.52 \times 10^{5}$ & $1.7 \times 10^{6} \pm 2.4 \times 10^{5 \dagger}$ & $0.33 \times 10^{6} \pm 0.21 \times 10^{5 \dagger}$ & $0.41 \times 10^{6} \pm 1.9 \times 10^{5 \sqrt{ }}$ \\
\hline MG132 & $1.2 \times 10^{6} \pm 3.6 \times 10^{5}$ & $1.05 \times 10^{6} \pm 1.2 \times 10^{5} *$ & $1.4 \times 10^{6} \pm 2.9 \times 10^{5} * *$ & $1.3 \times 10^{6} \pm 0.32 \times 10^{5 *}$ \\
\hline CA-074ME & $0.79 \times 10^{6} \pm 0.65 \times 10^{5}$ & $1.4 \times 10^{6} \pm 1.4 \times 10^{5}$ & $0.96 \times 10^{6} \pm 1.9 \times 10^{5 *}$ & $1.9 \times 10^{6} \pm 4.8 \times 10^{5 * *}$ \\
\hline MG132 + CA-074ME & $1.5 \times 10^{6} \pm 0.69 \times 10^{5}$ & $1.4 \times 10^{6} \pm 2.7 \times 10^{5}$ & $1.7 \times 10^{6} \pm 3.0 \times 10^{5 * * *}$ & $2.3 \times 10^{6} \pm 2.9 \times 10^{5 * * *}$ \\
\hline
\end{tabular}

${ }^{*} P<0.05$

${ }^{* *} P<0.01$

${ }^{* * * *} P<0.001$ vs. respective no-treatment value

${ }^{\dagger} P<0.05$ vs. normoxia no treatment value.

$\sqrt{ }_{P}<0.05$ vs. hypoxia no treatment value (one-way ANOVA with Bonferroni's post-test). 
A
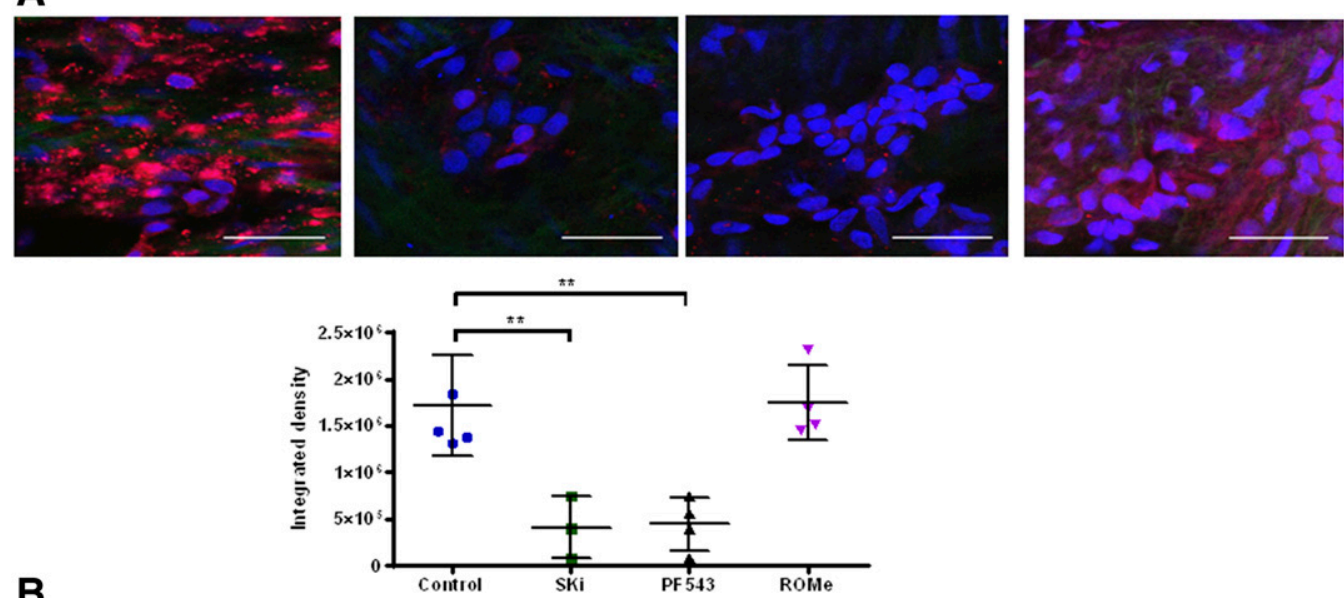

B
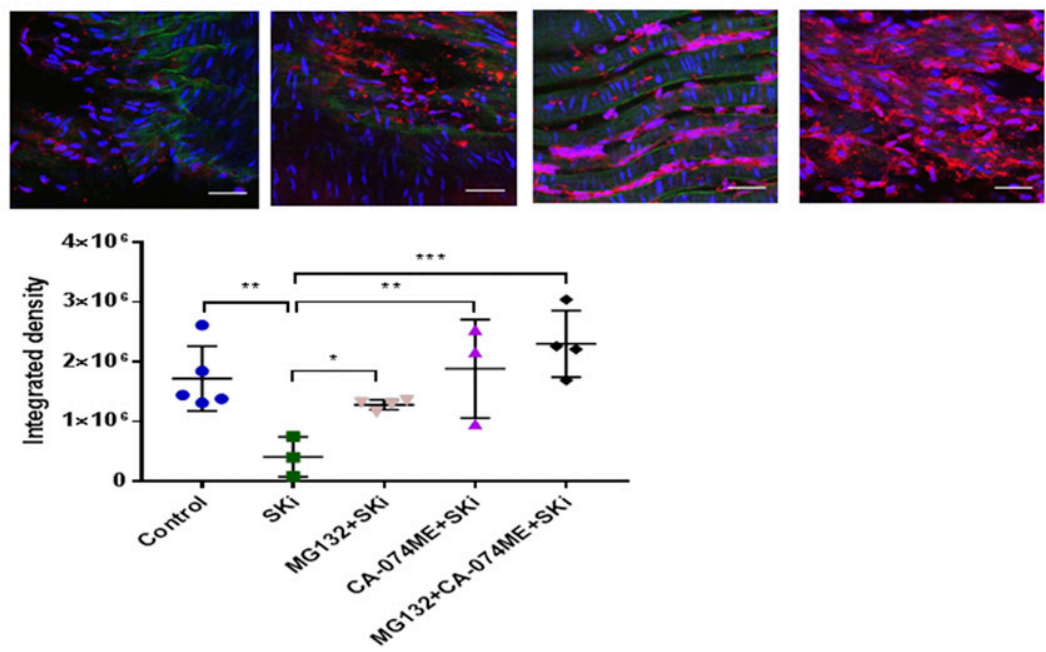

Fig. 8. (A) Representative immunofluorescent images showing expression of SK1 (red) in rat coronary artery endothelium under hypoxic conditions (left). Nuclei appear blue due to addition of Syto 61 nuclear stain. Treatment with SKi or the selective SK1 inhibitor PF543 (both at $10 \mu \mathrm{M}$ for 30 minutes) significantly reduced the hypoxia-induced increase in SK1 expression while ROMe (10 $\mu \mathrm{M}$ for 30 minutes) had no effect (right). (Lower panel) Scatter plot showing quantitative fluorescence measurements of SK1 and effects of hypoxia and drugs. ${ }^{* *} P<0.01$ vs. hypoxia alone as determined by one-way ANOVA with Bonferroni's post-test. Results are representative of three to four separate experiments. Scale bar, $30 \mu \mathrm{m}$. (B) Under hypoxic conditions, the effect of SKi on the expression of SK1, shown as red fluorescence, could be significantly reversed by the proteasomal inhibitor MG132, the lysosomal inhibitor CA-074ME, or a combination of MG132 and CA-074ME (all added at $10 \mu \mathrm{M}$ for 30 minutes). (Lower panel) Scatter plot showing quantitative fluorescence measurements of SK1 and effects of hypoxia and drugs. $* P<0.05 ; * * P<0.01$; $* * * P<0.001 \mathrm{vs.} \mathrm{SKi}+$ hypoxia alone.

cathepsin B. In contrast, we have shown that SKi induces proteasomal degradation of SK1 in human pulmonary artery smooth muscle cells, prostate cells, and breast cancer cells (Loveridge et al., 2010; Byun et al., 2013), which were insensitive to CA-074ME. To determine whether the SK inhibitors PF-543 and SKi reduced SK1 expression by enhancing its degradation, we pretreated vessels with a combination of CA074ME and the proteasome inhibitor MG132 prior to 30 minutes of hypoxia. This combination prevented the effects of PF-543 (Fig. 7) and SKi (Fig. 8) on SK1 expression in aortic endothelial cells and coronary endothelial cells, respectively. Indeed, in coronary endothelial cells, MG132 or CA-074ME alone significantly reversed the effects of SKi on hypoxiainduced upregulation of SK1, suggesting that degradation by both the proteasome and the lysosome are important in SK1 turnover under hypoxic conditions in these cells. The immunofluorescence data add weight to our hypothesis that generation of vasodilator S1P by SK1 in the endothelium causes enhanced relaxation in rings exposed to hypoxia via $\mathrm{S} \mathrm{P}_{3}$, which likely involves privileged access of endothelial cell-derived S1P to these receptors. Inhibitors of SK1 prevent this by forcing degradation of SK1, thereby theoretically reducing $\mathrm{S1P}$ generation by the endothelium and activation of $\mathrm{S}_{\mathrm{P}}$. Thus, when exposed to hypoxia, the enhanced relaxation to S1P is likely due a combination of exogenously added S1P and endogenously generated and exported S1P.

In conclusion, this study shows that acute reversible hypoxia increases SK1 expression in rat aortic endothelium and enhances vasorelaxation responses to S1P. SK1, but not SK2, was involved in S1P-induced relaxation under normoxia and hypoxia. A potent inhibitor of SK1 (PF-543) blocked the upregulation of SK1 in response to hypoxia, likely through increased proteasomal/lysosomal degradation of the enzyme and reduced relaxation of the artery to S1P; this effect was not observed with an SK2 inhibitor. Overall, this study demonstrates that hypoxia upregulates the SK1/S1P system, which has effects on vascular function. These results identify S1P receptors as potential therapeutic targets in ischemia/ reperfusion and have relevance for events such as ischemic stroke, myocardial infarction, and perhaps even conditions 
where tissues are chronically or periodically exposed to lower oxygen tension such as angina and transient ischemic attack.

\section{Authorship Contributions}

Participated in research design: Alganga, S. Pyne, N. J. Pyne,

Kennedy.

Conducted experiments: Alganga, Almabrouk, Katwan, Kennedy.

Performed data analysis: Alganga, Daly, S. Pyne, N. J. Pyne,

Kennedy.

Wrote or contributed to the writing of the manuscript: Alganga, S.

Pyne, N. J. Pyne, Kennedy.

\section{References}

Ahmad M, Long JS, Pyne NJ, and Pyne S (2006) The effect of hypoxia on lipid phosphate receptor and sphingosine kinase expression and mitogen-activated protein kinase signaling in human pulmonary smooth muscle cells. Prostaglandins Other Lipid Mediat 79:278-286.

Alewijnse AE and Peters SL (2008) Sphingolipid signalling in the cardiovascular system: good, bad or both? Eur J Pharmacol 585:292-302.

Anelli V, Gault CR, Cheng AB, and Obeid LM (2008) Sphingosine kinase 1 is upregulated during hypoxia in U87MG glioma cells. Role of hypoxia-inducible factors 1 and 2. $J$ Biol Chem 283:3365-3375.

Arribas SM, Daly CJ, González MC, and McGrath JC (2007) Imaging the vascular wall using confocal microscopy. J Physiol 584:5-9.

Busse R, Pohl U, Kellner C, and Klemm U (1983) Endothelial cells are involved in the vasodilatory response to hypoxia. Pflugers Arch 397:78-80.

Byun H-S, Pyne S, Macritchie N, Pyne NJ, and Bittman R (2013) Novel sphingosinecontaining analogues selectively inhibit sphingosine kinase (SK) isozymes, induce SK1 proteasomal degradation and reduce DNA synthesis in human pulmonary arterial smooth muscle cells. Medchemcomm 4:1394-1399.

Chawla S and Saxena S (2015) Differential modulation of $\mathrm{S}_{\mathrm{PR}} \mathrm{P}_{(1-5)}$ and specific activities of SphK and nSMase in pulmonary and cerebral tissues of rats exposed to hypobaric hypoxia. Lipids 50:39-48.

Coleman RA, Humphrey PP, Kennedy I, Levy GP, and Lumley P (1981) Comparison of the actions of U-46619, a prostaglandin H2-analogue, with those of prostaglandin $\mathrm{H} 2$ and thromboxane $\mathrm{A} 2$ on some isolated smooth muscle preparations. Br J Pharmacol 73:773-778.

Dantas AP, Igarashi J, and Michel T (2003) Sphingosine 1-phosphate and control of vascular tone. Am J Physiol Heart Circ Physiol 284:H2045-H2052.

Daut J, Maier-Rudolph W, von Beckerath N, Mehrke G, Günther K, and GoedelMeinen L (1990) Hypoxic dilation of coronary arteries is mediated by ATP-sensitive potassium channels. Science 247:1341-1344.

Ding G, Sonoda H, Yu H, Kajimoto T, Goparaju SK, Jahangeer S, Okada T, and Nakamura S (2007) Protein kinase D-mediated phosphorylation and nuclear export of sphingosine kinase 2. J Biol Chem 282:27493-27502.

di Villa Bianca R, Sorrentino R, Sorrentino R, Imbimbo C, Palmieri A, Fusco F, Maggi M, De Palma R, Cirino G, and Mirone V (2006) Sphingosine 1-phosphate induces endothelial nitric-oxide synthase activation through phosphorylation in human corpus cavernosum. J Pharmacol Exp Ther 316:703-708.

Franco-Obregón A and López-Barneo J (1996) Low PO2 inhibits calcium channel activity in arterial smooth muscle cells. Am J Physiol 271:H2290-H2299.

French KJ, Schrecengost RS, Lee BD, Zhuang Y, Smith SN, Eberly JL, Yun JK, and Smith CD (2003) Discovery and evaluation of inhibitors of human sphingosine kinase. Cancer Res 63:5962-5969.

Furfine ES, Harmon MF, Paith JE, and Garvey EP (1993) Selective inhibition of constitutive nitric oxide synthase by L-NG-nitroarginine. Biochemistry 32: 8512-8517.

Gairhe S, Joshi SR, Bastola MM, McLendon JM, Oka M, Fagan KA, and McMurtry IF (2016) Sphingosine-1-phosphate is involved in the occlusive arteriopathy of pulmonary arterial hypertension. Pulm Circ 6:369-380.

Gao P, Peterson YK, Smith RA, and Smith CD (2012) Characterization of isoenzymeselective inhibitors of human sphingosine kinases. PLoS One 7:e44543.

Gasser R, Klein W, and Kickenweiz E (1993) Vasodilative response to hypoxia and simulated ischemia is mediated by ATP-sensitive $\mathrm{K}^{+}$channels in Guinea pig thoracic aorta. Angiology 44:228-243.

Gasser R, Köppel H, Brussee H, Grisold M, Holzmann S, and Klein W (1998) EDRF does not mediate coronary vasodilation secondary to simulated ischemia: a study on KATP channels and N $\omega$-nitro-L-arginine on coronary perfusion pressure in isolated Langendorff-perfused Guinea-pig hearts. Cardiovasc Drugs Ther 12: 279-284.

Gräser T and Rubanyi GM (1993) Hypoxic contraction in isolated rat abdominal aorta: role of endothelium and vascular smooth muscle. Endothelium 1:99-107.

Gräser T and Vanhoutte PM (1991) Hypoxic contraction of canine coronary arteries: role of endothelium and cGMP. Am J Physiol 261:H1769-H1777.

Hannun YA and Obeid LM (2002) The ceramide-centric universe of lipid-mediated cell regulation: stress encounters of the lipid kind. J Biol Chem 277:25847-25850.

Hemmings DG, Xu Y, and Davidge ST (2004) Sphingosine 1-phosphate-induced vasoconstriction is elevated in mesenteric resistance arteries from aged female rats. Br J Pharmacol 143:276-284.

Herrera GM and Walker BR (1998) Involvement of L-type calcium channels in hypoxic relaxation of vascular smooth muscle. J Vasc Res 35:265-273.

Igarashi J, Bernier SG, and Michel T (2001) Sphingosine 1-phosphate and activation of endothelial nitric-oxide synthase. Differential regulation of Akt and MAP kinase pathways by EDG and bradykinin receptors in vascular endothelial cells. J Biol Chem 276:12420-12426.
Igarashi J and Michel T (2000) Agonist-modulated targeting of the EDG-1 receptor to plasmalemmal caveolae. eNOS activation by sphingosine 1-phosphate and the role of caveolin-1 in sphingolipid signal transduction. J Biol Chem 275:32363-32370.

Igarashi N, Okada T, Hayashi S, Fujita T, Jahangeer S, and Nakamura S (2003) Sphingosine kinase 2 is a nuclear protein and inhibits DNA synthesis. J Biol Chem 278:46832-46839.

Jo E, Bhhatarai B, Repetto E, Guerrero M, Riley S, Brown SJ, Kohno Y, Roberts E, Schürer SC, and Rosen H (2012) Novel selective allosteric and bitopic ligands for the $\mathrm{S}_{1} \mathrm{P}_{3}$ receptor. ACS Chem Biol 7:1975-1983.

Karliner JS (2013) Sphingosine kinase and sphingosine 1-phosphate in the heart: a decade of progress. Biochim Biophys Acta 1831:203-212.

Kerkhof CJ, Van Der Linden PJ, and Sipkema P (2002) Role of myocardium and endothelium in coronary vascular smooth muscle responses to hypoxia. $\mathrm{Am}$ $J$ Physiol Heart Circ Physiol 282:H1296-H1303.

Kim MY, Liang GH, Kim JA, Kim YJ, Oh S, and Suh SH (2006) Sphingosine-1phosphate activates $\mathrm{BK}_{\mathrm{Ca}}$ channels independently of $\mathrm{G}$ protein-coupled receptor in human endothelial cells. Am J Physiol Cell Physiol 290:C1000-C1008.

Kohama T, Olivera A, Edsall L, Nagiec MM, Dickson R, and Spiegel S (1998) Molecular cloning and functional characterization of murine sphingosine kinase. $J$ Biol Chem 273:23722-23728.

Li N and Zhang F (2016) Implication of sphingosin-1-phosphate in cardiovascular regulation. Front Biosci 21:1296-1313.

Lim KG, Sun C, Bittman R, Pyne NJ, and Pyne S (2011) (R)-FTY720 methyl ether is a specific sphingosine kinase 2 inhibitor: effect on sphingosine kinase 2 expression in HEK 293 cells and actin rearrangement and survival of MCF-7 breast cancer cells. Cell Signal 23:1590-1595.

Lin H, Baby N, Lu J, Kaur C, Zhang C, Xu J, Ling E-A, and Dheen ST (2011) Expression of sphingosine kinase 1 in amoeboid microglial cells in the corpus callosum of postnatal rats. J Neuroinflammation 8:13.

Liu H, Sugiura M, Nava VE, Edsall LC, Kono K, Poulton S, Milstien S, Kohama T, and Spiegel S (2000) Molecular cloning and functional characterization of a novel mammalian sphingosine kinase type 2 isoform. J Biol Chem 275:19513-19520.

Long JS, Edwards J, Watson C, Tovey S, Mair KM, Schiff R, Natarajan V, Pyne NJ, and Pyne S (2010) Sphingosine kinase 1 induces tolerance to human epidermal growth factor receptor 2 and prevents formation of a migratory phenotype in response to sphingosine 1-phosphate in estrogen receptor-positive breast cancer cells. Mol Cell Biol 30:3827-3841.

Loveridge C, Tonelli F, Leclercq T, Lim KG, Long JS, Berdyshev E, Tate RJ, Natarajan V, Pitson SM, Pyne NJ, et al. (2010) The sphingosine kinase 1 inhibitor 2-( $p$-hydroxyanilino)-4-( $p$-chlorophenyl)thiazole induces proteasomal degradation of sphingosine kinase 1 in mammalian cells. J Biol Chem 285:38841-38852.

Lynch FM, Austin C, Heagerty AM, and Izzard AS (2006) Adenosine- and hypoxiainduced dilation of human coronary resistance arteries: evidence against the involvement of $\mathrm{K}_{\mathrm{ATP}}$ channels. $\mathrm{Br} J$ Pharmacol 147:455-458.

Mair KM, Robinson E, Kane KA, Pyne S, Brett RR, Pyne NJ, and Kennedy S (2010) Interaction between anandamide and sphingosine-1-phosphate in mediating vasorelaxation in rat coronary artery. Br J Pharmacol 161:176-192.

Marriott JF (1989) The effects of verapamil upon noradrenaline-induced contraction of the rat isolated aorta following acute and prolonged alterations in $\mathrm{PO} 2 . \mathrm{Br}$ $J$ Pharmacol 98:1101-1108.

Messina EJ, Sun D, Koller A, Wolin MS, and Kaley G (1992) Role of endotheliumderived prostaglandins in hypoxia-elicited arteriolar dilation in rat skeletal muscle. Circ Res 71:790-796.

Murakami A, Takasugi H, Ohnuma S, Koide Y, Sakurai A, Takeda S, Hasegawa T, Sasamori J, Konno T, Hayashi K, et al. (2010) Sphingosine 1-phosphate (S1P) regulates vascular contraction via $\mathrm{S}_{3} \mathrm{P}_{3}$ receptor: investigation based on a new $\mathrm{S}_{1} \mathrm{P}_{3}$ receptor antagonist. Mol Pharmacol 77:704-713.

Muramatsu M, Iwama Y, Shimizu K, Asano H, Toki Y, Miyazaki Y, Okumura K, Hashimoto H, and Ito T (1992) Hypoxia-elicited contraction of aorta and coronary artery via removal of endothelium-derived nitric oxide. Am J Physiol 263: H1339-H1347.

Nofer JR, Geigenmüller S, Göpfert C, Assmann G, Buddecke E, and Schmidt A (2003) High density lipoprotein-associated lysosphingolipids reduce E-selectin expression in human endothelial cells. Biochem Biophys Res Commun 310:98-103.

Nofer JR, van der Giet M, Tölle M, Wolinska I, von Wnuck Lipinski K, Baba HA, Tietge UJ, Gödecke A, Ishii I, Kleuser B, et al. (2004) HDL induces NO-dependent vasorelaxation via the lysophospholipid receptor $\mathrm{S}_{3} \mathrm{P}_{3}$. J Clin Invest 113:569-581.

Olivera A, Kohama T, Tu Z, Milstien S, and Spiegel S (1998) Purification and characterization of rat kidney sphingosine kinase. J Biol Chem 273:12576-12583.

Pearce WJ, Ashwal S, Long DM, and Cuevas J (1992) Hypoxia inhibits calcium influx in rabbit basilar and carotid arteries. Am J Physiol 262:H106-H113.

Pitson SM, Moretti PA, Zebol JR, Lynn HE, Xia P, Vadas MA, and Wattenberg BW (2003) Activation of sphingosine kinase 1 by ERK1/2-mediated phosphorylation. EMBO J 22:5491-5500.

Pyla R, Pichavaram P, Fairaq A, Park MA, Kozak M, Kamath V, Patel VS, and Segar L (2015) Altered energy state reversibly controls smooth muscle contractile function in human saphenous vein during acute hypoxia-reoxygenation: role of glycogen, AMP-activated protein kinase, and insulin-independent glucose uptake Biochem Pharmacol 97:77-88.

Pyne S and Pyne NJ (2011) Translational aspects of sphingosine 1-phosphate biology. Trends Mol Med 17:463-472.

Ren S, Xin C, Pfeilschifter J, and Huwiler A (2010) A novel mode of action of the putative sphingosine kinase inhibitor 2-(p-hydroxyanilino)-4-(p-chlorophenyl) thiazole (SKI II): induction of lysosomal sphingosine kinase 1 degradation. Cell Physiol Biochem 26:97-104.

Roviezzo F, Bucci M, Delisle C, Brancaleone V, Di Lorenzo A, Mayo IP, Fiorucci S, Fontana A, Gratton JP, and Cirino G (2006) Essential requirement for sphingosine kinase activity in eNOS-dependent NO release and vasorelaxation. FASEB $J$ 20:340-342.

Salomone S, Potts EM, Tyndall S, Ip PC, Chun J, Brinkmann V, and Waeber C (2008) Analysis of sphingosine 1-phosphate receptors involved in constriction of isolated 
cerebral arteries with receptor null mice and pharmacological tools. $\mathrm{Br}$ $J$ Pharmacol 153:140-147.

Sanna MG, Liao J, Jo E, Alfonso C, Ahn MY, Peterson MS, Webb B, Lefebvre S, Chun J, Gray N, et al. (2004) Sphingosine 1-phosphate (S1P) receptor subtypes $\mathrm{S}_{1} \mathrm{P}_{1}$ and $\mathrm{S}_{1} \mathrm{P}_{3}$, respectively, regulate lymphocyte recirculation and heart rate. J Biol Chem 279:13839-13848.

Schneider CA, Rasband WS, and Eliceiri KW (2012) NIH Image to ImageJ: 25 years of image analysis. Nat Methods 9:671-675.

Schnüte ME, McReynolds MD, Kasten T, Yates M, Jerome G, Rains JW, Hall T, Chrencik J, Kraus M, Cronin CN, et al. (2012) Modulation of cellular S1P levels with a novel, potent and specific inhibitor of sphingosine kinase-1. Biochem J 444:79-88.

Schwalm S, Döll F, Römer I, Bubnova S, Pfeilschifter J, and Huwiler A (2008) Sphingosine kinase-1 is a hypoxia-regulated gene that stimulates migration of human endothelial cells. Biochem Biophys Res Commun 368:1020-1025.

Sillau AH, McCullough RE, Dyckes R, White MM, and Moore LG (2002) Chronic hypoxia increases MCA contractile response to U-46619 by reducing NO production and/or activity. J Appl Physiol (1985) 92:1859-1864.

Tölle M, Levkau B, Keul P, Brinkmann V, Giebing G, Schönfelder G, Schäfers M, von Wnuck Lipinski K, Jankowski J, Jankowski V, et al. (2005) Immunomodulator FTY720 Induces eNOS-dependent arterial vasodilatation via the lysophospholipid receptor $\mathrm{S}_{1} \mathrm{P}_{3}$. Circ Res 96:913-920.
Tonelli F, Lim KG, Loveridge C, Long J, Pitson SM, Tigyi G, Bittman R, Pyne S, and Pyne NJ (2010) FTY720 and (S)-FTY720 vinylphosphonate inhibit sphingosine kinase 1 and promote its proteasomal degradation in human pulmonary artery smooth muscle, breast cancer and androgen-independent prostate cancer cells. Cell Signal 22:1536-1542.

Totzeck M, Hendgen-Cotta UB, Kelm M, and Rassaf T (2014) Crosstalk between nitrite, myoglobin and reactive oxygen species to regulate vasodilation under hypoxia. PLoS One 9:e105951.

Wacker BK, Park TS, and Gidday JM (2009) Hypoxic preconditioning-induced cerebral ischemic tolerance: role of microvascular sphingosine kinase 2. Stroke 40: 3342-3348.

Zhang R, Li L, Yuan L, and Zhao M (2016) Hypoxic preconditioning protects cardiomyocytes against hypoxia/reoxygenation-induced cell apoptosis via sphingosine kinase 2 and FAK/AKT pathway. Exp Mol Pathol 100:51-58.

Address correspondence to: Dr. S. Kennedy, Institute of Cardiovascular and Medical Sciences, College of Medical, Veterinary \& Life Sciences, University of Glasgow, Glasgow G12 8QQ, UK. E-mail: simon.kennedy@ glasgow.ac.uk 